\title{
Colagem ortodôntica em esmalte com presença ou ausência de contaminação salivar: é necessário o uso de adesivo auto-condicionante ou de adesivo hidrofílico?
}

\author{
Cristiane Becher Rosa*, Roberto Amarante Costa Pinto**, Fernando Antonio Lima Habib**
}

\begin{abstract}
Resumo
Objetivo: o objetivo deste trabalho foi avaliar a resistência ao cisalhamento da colagem ortodôntica de um adesivo hidrofílico (Transbond Moisture-Insensitive Primer, 3M Unitek, Monrovia, Califórnia), de um adesivo auto-condicionante (Transbond Self-Etching Primer, 3M Unitek, Monrovia, Califórnia), e sem uso de adesivo, em superfícies de esmalte secas ou contaminadas por saliva. Metodologia: incisivos bovinos (60) foram divididos em 6 grupos: (1) controle sem contaminação salivar (sem adesivo), (2) controle com contaminação salivar (sem adesivo), (3) adesivo auto-condicionante sem contaminação salivar, (4) adesivo autocondicionante com contaminação salivar antes do adesivo, (5) adesivo hidrofílico sem contaminação salivar e (6) adesivo hidrofílico com contaminação salivar antes do adesivo. Braquetes metálicos foram colados com compósito (Transbond XT, 3M Unitek, Monrovia, Califórnia). Após a colagem, os corpos-de prova foram armazenados a $37 \pm 1^{\circ} \mathrm{C}$ em ambiente úmido até a realização do teste de cisalhamento. Diferença estatística foi determinada com valor de probabilidade de 0,05 ou menos ( $\mathrm{p} \leq 0,05$ ). Resultados: em esmalte sem contaminação foram encontrados resultados semelhantes entre o controle (1) e o adesivo auto-condicionante (3), enquanto o adesivo hidrofílico (5) apresentou maior força de cisalhamento. Com a contaminação salivar, uma diferença significativa foi encontrada entre o grupo controle (2) e o adesivo auto-condicionante (4), no entanto, nenhuma diferença foi encontrada entre os adesivos autocondicionante (4) e hidrofílico (6). Conclusão: desta forma, com o controle de umidade, não é necessário o uso de um adesivo para se atingir uma adesão aceitável. Em situações clínicas onde há risco de contaminação salivar, ambos adesivos podem ser usados.
\end{abstract}

Palavras-chave: Adesivos. Resinas compostas. Resistência ao cisalhamento. Saliva. Esmalte dentário.

\footnotetext{
* Especialista em Ortodontia pelo Curso de Especialização do Centro de Ortodontia e Ortopedia Facial Professor José Édimo Soares

Martins - FO.UFBA.

** Professor do Curso de Especialização do Centro de Ortodontia e Ortopedia Facial Professor José Édimo Soares Martins - FO.UFBA.
} 


\section{INTRODUÇÃO}

Toda colagem ortodôntica envolve no mínimo duas interfaces: esmalte/compósito e braquete/ compósito. Se um adesivo é utilizado, outra interface - a do adesivo/compósito - é formada ${ }^{19}$.

Os adesivos podem aumentar a adesão na colagem, diminuindo o número de descolagens durante o tratamento ortodôntico. O resultado disto é um maior número de falhas na interface esmalte/compósito, com conseqüente aumento do índice de fraturas de esmalte ${ }^{5,16}$. Uma menor quantidade de compósito na superfície dentária pode ser uma vantagem, por facilitar o processo de limpeza do dente ${ }^{3}$, mas deve-se lembrar que a integridade do esmalte precisa ser preservada ao serem removidos os braquetes e os acessórios ortodônticos ${ }^{5,16}$. O ideal seria minimizar a perda de esmalte dentário nos estágios de colagem, descolagem e remoção de compósito residual, permanecendo a superfície dentária com grau de rugosidade original do dente ${ }^{11}$.

Manter a superfície do esmalte completamente livre de contaminação por umidade, todavia, é difícil, principalmente na colagem de braquetes e acessórios durante procedimentos cirúrgicos de dentes impactados ${ }^{18}$, em superfícies dentárias linguais ${ }^{13,17}$, em segundos molares e em dentes parcialmente irrompidos ${ }^{7,11}$. Falhas na colagem de acessórios e braquetes ortodônticos têm sido geralmente atribuídas à contaminação do esmalte. Materiais têm sido desenvolvidos para superar a umidade e contaminantes presentes na cavidade bucal ${ }^{23}$. Os adesivos hidrofilicos poderiam, desta forma, ser usados para aumentar a força de adesão, que estaria comprometida em um esmalte contaminado.

Atualmente adesivos hidrofílicos para uso em esmalte foram desenvolvidos com objetivo de produzir adesão adequada, havendo ou não a presença de umidade. Estes adesivos apresentam acetona ou etanol como solventes e, hipoteticamente, seriam capazes de se deslocar e se difundir através do filme salivar para atingir a hidroxiapatita e promover uma adesão adequada após a polimerização ${ }^{23}$. O Transbond Moisture-Insensitive Primer
(Transbond MIP - 3M Unitek) é, de acordo com o fabricante, um adesivo hidrofílico que pode ser usado em superfícies de esmalte secas ou contaminadas por saliva ou água.

Outro sistema adesivo aplicado nos procedimentos de colagem ortodôntica é o adesivo autocondicionante ou self-etching primer (SEP), que foi introduzido na Dentística para ser usado em restaurações de compósito em esmalte e dentina ${ }^{25}$. Os sistemas adesivos auto-condicionantes possuem monômeros resinosos ácidos em sua composição que, simultaneamente, desmineralizam e penetram no substrato dentário, sem a necessidade de uma aplicação isolada de um ácido para produzir as porosidades nos tecidos dentários ${ }^{7}$.

O SEP com finalidade ortodôntica Transbond Plus Self-Etching Primer (Transbond SEP - 3M Unitek), de acordo com o fabricante, pode ser utilizado em superfícies de esmalte seco ou úmido. As vantagens do SEP incluem, ainda, um menor número de passos na técnica de adesão, o que resultaria em menor número de erros, economia de tempo ${ }^{2,4,6,25}$, maior conforto ao paciente e maior controle de umidade ${ }^{13}$.

Estudos anteriores avaliando o Transbond SEP e Transbond MIP, em esmalte seco e contaminado, têm mostrado resultados conflitantes em relação a qual adesivo seria mais eficiente em ambos ambientes. A comparação destes adesivos com um grupo controle sem a presença de um adesivo ainda não foi avaliada, já que em estudos prévios um adesivo hidrofóbico foi usado como grupo contro$1 \mathrm{e}^{7,20,22,25}$.

O objetivo deste estudo foi avaliar se a presença de um adesivo é necessária para se obter uma força de adesão aceitável na colagem ortodôntica em esmalte com diferentes tratamentos, seco ou contaminado por saliva e, caso seja, qual adesivo seria mais satisfatório.

\section{MATERIAL E MÉTODOS}

Foram utilizados na amostra 60 dentes bovinos. Os dentes foram extraídos, limpos e armazenados 
em solução aquosa de timol a 0,1\%, em temperatura ambiente até a realização do experimento.

Antes dos procedimentos de colagem, a amostra foi preparada para possibilitar o ensaio de cisalhamento. Foi necessário determinar a área de colagem na coroa das unidades dentárias, para que esta área fosse aplainada. A altura da coroa clínica de cada dente foi medida com referência na borda incisal e no ponto mais inferior da junção amelocementária. A metade desta distância determinou o ponto central da superfície vestibular, que foi a região eleita para colagem e, conseqüentemente, para o aplainamento dentário. Um anel, confeccionado a partir de um tubo de filme fotográfico, foi posicionado sobre a coroa de cada dente e resina acrílica foi vazada no seu interior, promovendo a inclusão da coroa na resina. A face vestibular de cada dente foi parcialmente aplainada com lixa de madeira A180 e lixas d’água 220, 400 e 600 fixadas em um cortador de gesso, sob irrigação com água. Cada dente foi posicionado no centro de um anel de PVC contendo gesso tipo IV no seu interior, usando um dispositivo ${ }^{23}$ que permitia a fixação do dente no gesso com a face vestibular perpendicular à base do anel de PVC (Fig. 1).

Foi realizada profilaxia com pedra-pomes e taça de borracha em baixa rotação por 10 segundos, seguida de lavagem por 20 segundos com água proveniente da seringa tríplice do equipo odontológico e secagem com papel absorvente.

Os dentes foram divididos aleatoriamente em 6 grupos e os braquetes colados de acordo com um dos seis protocolos:

- Grupo 1 - controle (sem contaminação salivar): o esmalte foi condicionado com ácido fosfórico a 37\% (Alfa Etch Gel DFL) por 30 segundos, lavado por 20 segundos e seco com papel absorvente. Foi utilizado o compósito fotopolimerizável Transbond XT e não houve aplicação de adesivo ou contaminação da superfície do esmalte com saliva.

- Grupo 2 - controle (com contaminação salivar): após o condicionamento ácido, lavagem e secagem, a superfície do esmalte foi contaminada por 15 segundos com saliva humana coletada do próprio pesquisador em um frasco. A coleta da saliva foi realizada no momento de cada colagem a partir de uma hora após as refeições. A saliva foi colocada na superfície de esmalte com um aplicador. Foi utilizado o compósito Transbond XT sem o uso de um adesivo.

- Grupo 3 - Transbond SEP (sem contaminação salivar): foi utilizado Transbond SEP (Fig. 2) e o compósito Transbond XT e não houve contaminação da superfície do esmalte com saliva.

- Grupo 4 - Transbond SEP (contaminação salivar antes do primer): antes da aplicação do Transbond SEP, a superfície do esmalte foi contaminada por 15 segundos com saliva. Transbond SEP foi aplicado e o Transbond XT utilizado como compósito.

- Grupo 5 - MIP (sem contaminação salivar): após condicionamento com ácido fosfórico a 37\%, lavagem e secagem da superfície do esmalte, foram aplicados MIP (Fig. 3) e o compósito Transbond XT,

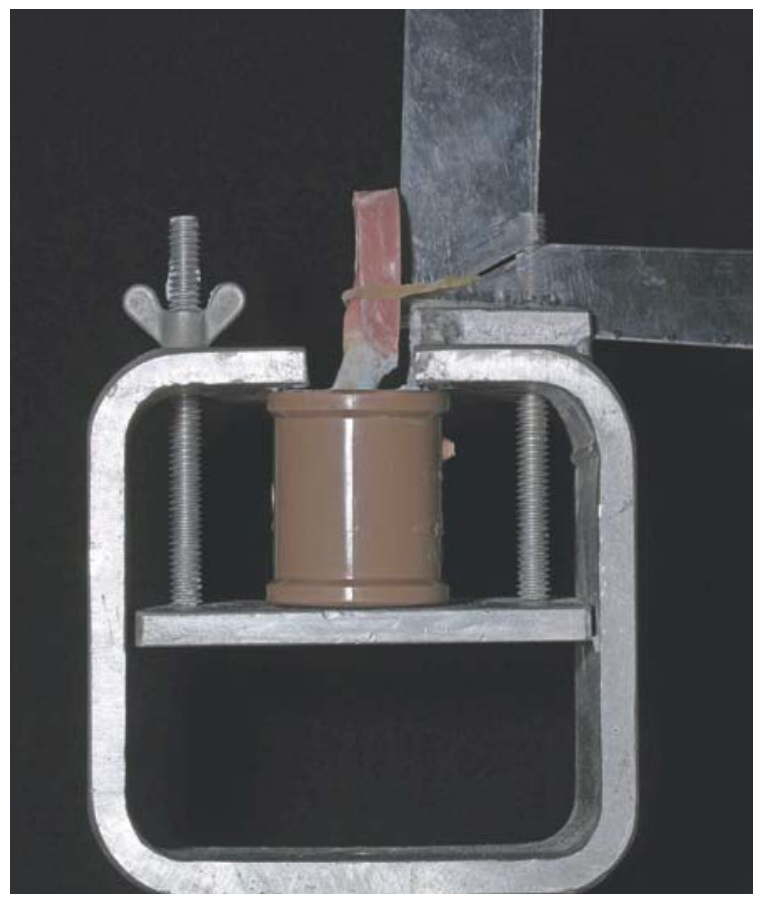

FIGURA 1 - Fixação do dente no gesso. 
não havendo contaminação da superfície do esmalte com saliva.

- Grupo 6 - MIP (contaminação salivar antes do primer): após condicionamento, lavagem e secagem, a superfície do esmalte foi contaminada por 15 segundos com saliva, o MIP aplicado e a colagem com o Transbond XT realizada.

O compósito Transbond XT foi aplicado na base do braquete, que foi colado ao dente após os procedimentos de condicionamento e aplicação de adesivo descritos acima nos grupos 1-6. O excesso de compósito foi removido com uma lâmina de bisturi e o compósito fotopolimerizado por 10 segundos de cada lado do braquete, totalizando 40 segundos. Foi utilizado um fotopolimerizador de luz fria (ULTRALED XP, Dabi Atlante, Ribeirão Preto, SP). Foram utilizados braquetes metálicos Edgewise de incisivo central superior para colagem com slot 0,022" (Morelli, São Paulo, SP, ref. 10.30.201), cuja área da base foi determinada pela medição com um paquímetro eletrônico e calculada em $14,282 \mathrm{~mm}^{2}$.

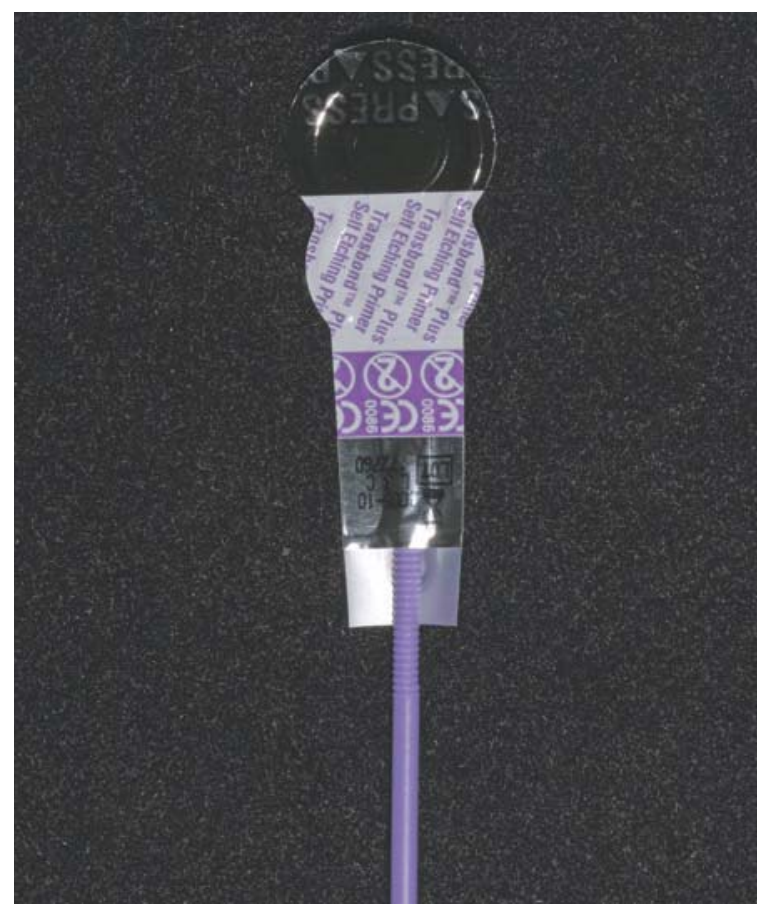

FIGURA 2 - Transbond SEP.
O posicionamento dos braquetes na superfície dentária em todos os grupos foi realizado com uma pinça de colagem, seguido de um fio retangular que foi encaixado no slot do braquete. Este fio estava colado em um esquadro de acrílico que foi introduzido em uma canaleta presente no dispositivo. Ao se encaixar no slot do braquete, era posicionado perpendicular à base do anel de PVC (Fig. 4, 5). Cada dente foi identificado marcandose, com caneta de retroprojetor no anel de PVC, o grupo ao qual pertencia. Após a colagem, os dentes foram armazenados em estufa a $37 \pm 1^{\circ} \mathrm{C}$ em ambiente úmido por 4 dias até a realização do ensaio mecânico.

Os anéis de PVC com os dentes foram posicionados novamente no dispositivo. $\mathrm{Na}$ base do dispositivo havia um orifício no centro, usado para fixar o mesmo à máquina de cisalhamento (Emic DL2000, São José dos Pinhais, PR) com um parafuso. A ponta ativa da máquina de ensaio universal foi posicionada sobre a borda superior do braquete o mais próximo possivel do dente, sem tocá-lo.

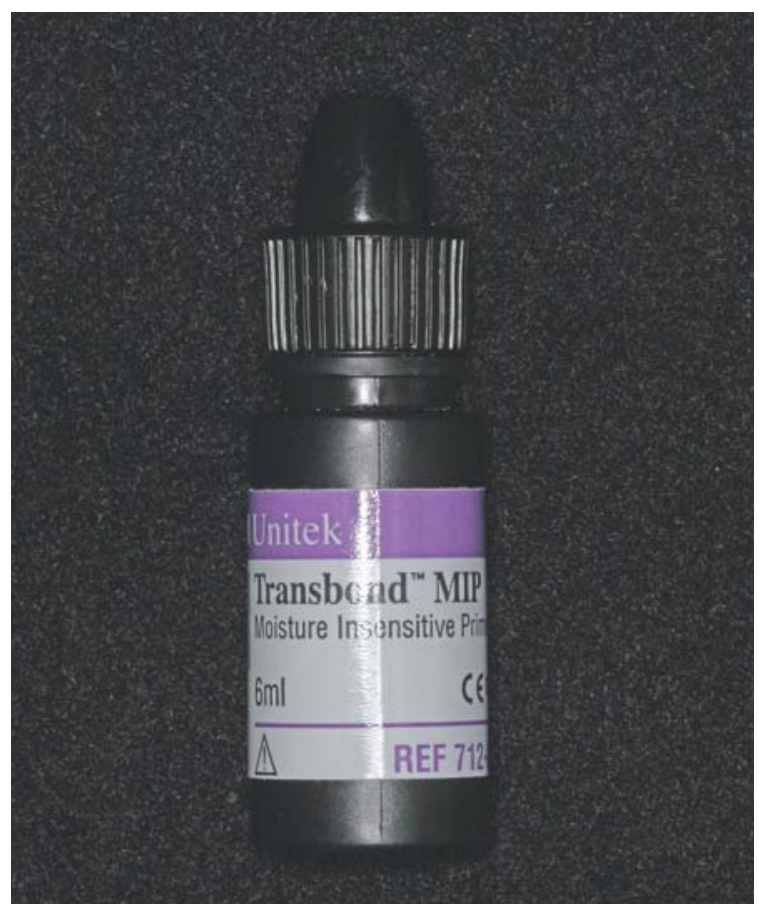

FIGURA 3 - Transbond MIP. 


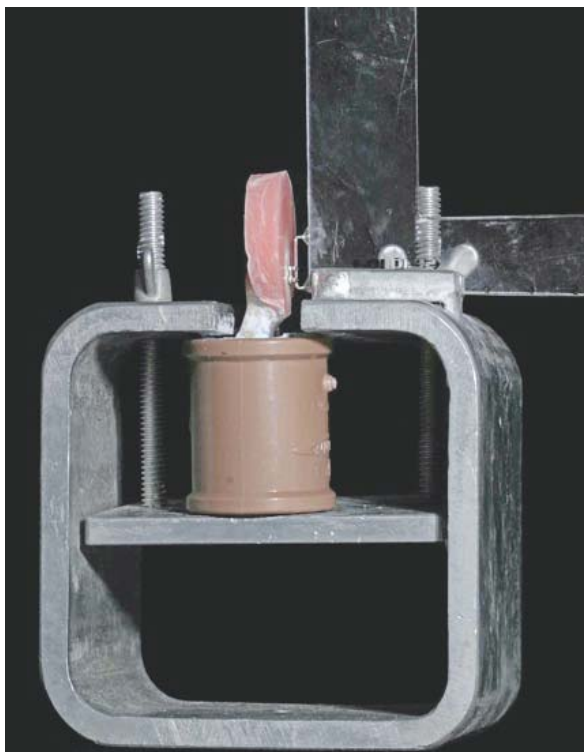

FIGURA 4 - Colagem do braquete.

Foi iniciada a descolagem dos braquetes com a máquina operando a uma velocidade de $1 \mathrm{~mm}$ por minuto. A força necessária para descolagem de cada braquete foi registrada. A resistência ao cisalhamento, expressa em Newton (N), foi dividida pela área da base do braquete em metro quadrado $\left(\mathrm{m}^{2}\right)$, e convertida em Megapascal (MPa) segundo a seguinte fórmula:

$$
\text { Resistência }(\mathrm{MPa})=\frac{\text { Força }(\mathrm{N})}{10^{6} \mathrm{x} \text { Ârea }\left(\mathrm{m}^{2)}\right.}
$$

Os dados obtidos foram, em seguida, submetidos à análise estatística através do teste $t$ de Student.

\section{Análise estatística}

Foi realizada estatística descritiva, incluindo a média, mediana e desvio-padrão, para cada um dos grupos testados.

O teste $t$ de Student foi utilizado para determinar se havia diferenças significativas presentes entre os grupos testados. Diferença significativa para o teste estatístico foi predeterminada em um valor de 0,05 ou menos $(p \leq 0,05)$.

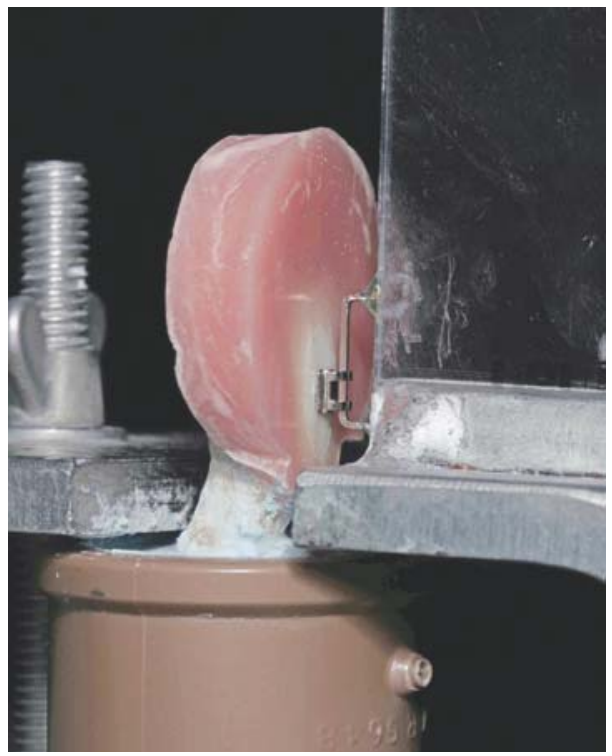

FIGURA 5 - Fio encaixado no slot do braquete durante colagem.

\section{RESULTADOS}

A estatística descritiva relacionada à força de cisalhamento dos seis grupos avaliados está representada na tabela 1 . Os resultados do teste $t$ de Student comparando a força de cisalhamento entre os grupos estão presentes nas tabelas 2 e 3 .

Ao comparar os grupos sem contaminação salivar (Tab. 2), os resultados do teste $t$ de Student indicam nenhuma diferença significativa entre o grupo controle 1 e o grupo 3 do Transbond SEP, apesar deste último apresentar uma média de força de cisalhamento maior (média 12,55 \pm 3,072MPa). Uma diferença estatística, no entanto, foi observada entre o grupo controle 1 e o grupo 5 do MIP ( $p=0,000)$ e entre o grupo 3 do Transbond SEP e o grupo 5 do MIP ( $\mathrm{p}=0,001)$.

Nos grupos com contaminação salivar (Tab. 3), uma diferença significativa foi encontrada na força de cisalhamento entre o grupo controle 2 e o grupo 4 do Transbond SEP $(p=0,000)$. Nenhuma diferença estatística foi observada entre o grupo controle 2 e o MIP 6 ( $\mathrm{p}=0,062)$. Comparações entre o grupo 4 do Transbond SEP e o grupo 6 do MIP mostraram não haver diferenças significativas também entre esses grupos $(\mathrm{p}=0,352)$. 
Tabela 1 - Estatística descritiva.

\begin{tabular}{cccc}
\hline grupos & média (MPa) & d.p. & mediana (MPa) \\
\hline 1) Controle (sem contaminação salivar) & 8,98 & 4,64 & 2,84 \\
2) Controle (com contaminação salivar) & 3,2 & 3,07 & 2,73 \\
3) Transbond SEP (sem contaminação salivar) & 12,55 & 2,42 & 12,57 \\
4) Transbond SEP (com contaminação salivar) & 16,12 & 3,11 & 16,14 \\
5) MIP (sem contaminação salivar) & 18,31 & 1,25 & 15,99 \\
6) MIP (com contaminação salivar) & 13,76 & & 15,96 \\
\hline
\end{tabular}

Tabela 2 - Teste $t$ de Student comparando a força de cisalhamento entre os grupos Controle, Transbond SEP e MIP em esmalte sem contaminação salivar.

\begin{tabular}{cccc}
\hline $\begin{array}{c}\text { grupos } \\
\text { sem contaminação }\end{array}$ & $\begin{array}{c}\text { comparação } \\
\text { entre os grupos }\end{array}$ & t & p \\
\hline 1) Controle & 1 vs 3 & $-2,03$ & 0,061 \\
3) Transbond SEP & 1 vs 5 & $-5,29$ & $0,000^{*}$ \\
5) MIP & 3 vs 5 & $-4,17$ & $0,001^{*}$ \\
\hline
\end{tabular}

* diferença estatisticamente significante $(p \leq 0,05)$.

\section{DISCUSSÃO}

O estudo presente demonstrou que, em superfícies de esmalte secas, nenhuma diferença foi encontrada entre o grupo controle, sem aplicação do adesivo (grupo 1), e o grupo do Transbond SEP (grupo 3). Ambos apresentaram uma resistência ao cisalhamento adequada para as necessidades ortodônticas, indicando que, em condições de controle de umidade, a aplicação de um adesivo não é imprescindível. Isto pode significar procedimentos clínicos mais simples, tempo de cadeira do paciente reduzido e menor custo. Estudos anteriores com outros agentes de união também indicaram não haver diferença estatística na força de adesão ao se usar ou não um adesivo antes da colagem ${ }^{10,15}$. Por outro lado, uma pesquisa demonstrou que com o uso de um adesivo formam-se tags maiores, resultando em valores maiores de resistência ao cisalhamento que, no entanto, podem implicar em um maior risco de fratura coesiva do esmalte durante os procedimentos de descolagem ${ }^{16}$.

No estudo presente, a aplicação do MIP em superfícies de esmalte secas resultou, porém, em
Tabela 3 - Teste $t$ de Student comparando a força de cisalhamento entre os grupos Controle, Transbond SEP e MIP em esmalte com contaminação salivar.

\begin{tabular}{cccc}
\hline $\begin{array}{c}\text { grupos } \\
\text { contaminados }\end{array}$ & $\begin{array}{c}\text { comparação } \\
\text { entre os grupos }\end{array}$ & t & p \\
\hline 2) Controle & 2 vs 4 & 110,3 & $0,000^{*}$ \\
4) Transbond SEP & 2 vs 6 & 4,22 & 0,062 \\
6) MIP & 4 vs 6 & 0,98 & 0,352 \\
\hline
\end{tabular}

* diferença estatisticamente significante $(p \leq 0,05)$.

uma força de cisalhamento acima dos padrões estabelecidos para uma adesão clinicamente aceitável. Apesar dos estudos in vitro não apresentarem os mesmos resultados obtidos clinicamente, é provável que a resistência necessária para a colagem a nível clínico esteja aquém da capacidade retentiva dos adesivos ${ }^{10,16}$. Forças de tração de 6 a $8 \mathrm{MPa}$ são consideradas adequadas para a maioria das aplicações ortodônticas, conforme dados obtidos por Reynolds em 1975,11,16,21,23.

Outro fator a se considerar é que braquetes e acessórios ortodônticos serão removidos em dois ou três anos, ao final do tratamento, tendo então a união adesivo/esmalte uma perspectiva diferente da considerada na Dentística Restauradora, em que esta união deve permanecer, preferencialmente, por toda a vida do indivíduo. Uma resistência máxima não é essencial na colagem ortodôntica ${ }^{16}$. Deve ser suficiente para suportar forças mastigatórias e ortodônticas ${ }^{16,23}$, mas também evitar fraturas de esmalte durante a descolagem ao término do tratamento ${ }^{5,16}$. Se a força da retenção micromecânica do adesivo for excessiva, durante a descolagem 
ocorrerá fratura, parcialmente na resina e parcialmente no esmalte ${ }^{8}$.

A colagem em esmalte contaminado com saliva sem a presença de um adesivo, todavia, resultou em uma resistência ao cisalhamento menor que o mínimo requerido para uma adesão aceitável.

Uma diferença significativa foi encontrada entre o controle (grupo 2) e o Transbond SEP (grupo 4), ambos com contaminação salivar antes da aplicação do adesivo. $\mathrm{O}$ valor alto de $\mathrm{t}(\mathrm{t}=110,3)$ indica que, entre todos os grupos que apresentaram diferenças estatísticas entre si nesta pesquisa, a diferença mais significativa foi encontrada ao se comparar estes dois grupos.

Nenhuma diferença estatística foi encontrada entre o controle (grupo 2) e o Transbond MIP (grupo 6), contaminados antes da aplicação do adesivo, apesar das médias destes grupos serem tão discrepantes. Isto pode ser explicado pelo alto desviopadrão presente nestes grupos, que conseqüentemente influenciou no resultado do teste estatístico $t$ de Student.

O uso de ambos adesivos, Transbond SEP ou MIP, parece ser adequado para situações que envolvam risco de contaminação salivar.

Há relatos, porém, de que a profundidade do condicionamento do esmalte criado pelo ácido fosfórico pode contribuir para a incidência de fraturas de esmalte ${ }^{1}$. Os adesivos auto-condicionantes não penetram ou dissolvem o esmalte na mesma profundidade dos sistemas adesivos convencionais que utilizam ácido fosfórico ${ }^{1,9} \mathrm{e}$, desta forma, minimizam a perda de esmalte durante o processo de condicionamento $^{1,9,12}$

Estudos futuros, utilizando os mesmos grupos desta pesquisa, poderiam avaliar a penetração dos tags de resina, assim como a quantidade de compósito presente na superfície do dente após a descolagem de braquetes. Com isto poder-se-ia informar se a ausência ou presença de um dos adesivos na colagem ortodôntica proporcionaria uma diferença significativa em relação à fratura de esmalte, já que em relação à resistência ao cisalhamento observada nesta pesquisa, muitos grupos não apresentaram diferenças estatísticas entre si.

\section{CONCLUSÃO}

1) A resistência ao cisalhamento de braquetes colados em superfícies de esmalte secas sem uso de adesivo foi satisfatória e não apresentou diferença significativa em relação ao adesivo auto-condicionante. Nenhuma diferença significativa foi encontrada entre o adesivo auto-condicionante e o grupo controle, enquanto o adesivo hidrofilico obteve valores maiores de força de cisalhamento.

2) A resistência ao cisalhamento da colagem em superfícies com presença de contaminação salivar sem uso de adesivo resultou, no entanto, em uma resistência abaixo daquela que a literatura mostra como mínima aceitável para aplicação ortodôntica.

3) O adesivo auto-condicionante, Transbond SEP e o hidrofílico Transbond MIP apresentaram altos valores de força de cisalhamento em esmalte seco e contaminado por saliva. Desta forma, ambos adesivos podem ser utilizados em situações clínicas em que o risco de contaminação salivar é evidente.
Enviado em: março de 2007 Revisado e aceito: junho de 2007 


\title{
Orthodontic bonding in dry and saliva contaminated enamel: is a self-etching primer or a moisture-insensitive primer necessary?
}

\begin{abstract}
Aim: The purpose of this study was to evaluate the shear bond strength of orthodontic bonding with the use of a hydrophilic primer (Transbond Moisture-Insensitive Primer, 3M Unitek, Monrovia, Calif.), a self-etching primer (Transbond Plus Self-etching Primer, 3M Unitek, Monrovia, Calif.) and without primer application, in dry and saliva contaminated enamel surfaces. Methods: Bovine incisors (60) were divided into 6 groups: (1) uncontaminated control (no primer), (2) control with saliva contamination (no primer), (3) uncontaminated self-etching primer, (4) saliva contamination before self-etching primer, (5) uncontaminated hydrophilic primer and (6) saliva contamination before hydrophilic primer. Stainless steel brackets were bonded with composite resin (Transbond XT, 3M Unitek, Monrovia, Calif.). After bonding, all samples were stored at $37 \pm 1^{\circ} \mathrm{C}$ in a humidity environment until the shear bond strength test. Results: Under dry uncontaminated enamel conditions comparable results were found between the control (1) and the self-etching primer (3), while the hydrophilic primer (5) presented higher bond strength. Under saliva contamination, a significant difference was found between the control (2) and the self-etching primer (4), however, there was no difference between the self-etching primer (4) and the hydrophilic primer group (6). Conclusion: Therefore, with moisture control, the use of a primer in order to achieve acceptable bond strength is not required. In clinical situations where there is a risk of saliva contamination either primer could be used.
\end{abstract}

Key words: Adhesives. Composite. Bond strength. Saliva. Dental enamel.

\section{REFERÊNCIAS}

1. AJLOUNI, R.; BISHARA, S. E.; OONSOMBAT, C.; DENEHY, G. E. Evaluation of modifying the bonding protocol of a new acid-etch primer on the shear bond strength of orthodontic brackets. Angle Orthod., Appleton, v. 74, no. 3, p. 410-413, 2004.

2. ALJUBOURI, Y. D.; MILLETT, D. T.; GILMOUR, W. H. Laboratory evaluation of a self-etching primer for orthodontic bonding. Eur. J. Orthod., Oxford, v. 25, no. 4, p. 411-415, Aug. 2003.

3. BISHARA, S. E.; GORDAN, V. V.; VONWALD, L.; OLSON, M. E. Effect of an acidic primer on shear bond strength of orthodontic brackets. Am. J. Orthod. Dentofacial Orthop. St. Louis, v. 114, no. 3, p. 243-247, Sep. 1998

4. BISHARA, S. E.; VONWALD, L.; LAFFOON, J. F.; WARREN, J. J. Effect of a self-etch primer/adhesive on the shear bond strength of orthodontic brackets. Am. J. Orthod. Dentofacial Orthop., St. Louis, v. 119, no. 6, p. 621-624, June 2001.

5. BISHARA, S. E.; AJLOUNI, R.; LAFFOON, J. F.; WARREN J. J. Effect of a flouride-releasing self-etch acidic primer on the shear bond strength of orthodontic brackets. Angle Orthod., Appleton, v. 72, no. 3, p. 199-202, 2002.

6. BISHARA, S. E.; AJLOUNI, R.; LAFFON, J. F.; WARREN, J. J. Comparison of shear bond strength of two self-etch primer/ adhesive systems. Angle Orthod., Appleton, v. 76, no. 1, p. 123-126, 2006

7. CACCIAFESTA, V.; SFONDRINI, M. F.; ANGELIS, M.; SCRIBANTE, A.; KLERSY, C. Effect of water and saliva contamination on shear bond strength of brackets bonded with conventional, hydrophilic and self-etching primers. Am. J. Orthod. Dentofacial Orthop., St. Louis, v. 123, no. 6, p. 633-640, June 2003.
8. DIEDRICH, P. Enamel alterations from bracket bonding and debonding: a study with the scanning electron microscope. Am. J. Orthod. Dentofacial Orthop., St. Louis, v. 79, no. 5 p. 500-522, May 1981.

9. DORMINEY, J. C.; DUNN, W. J.; TALOUMIS, L. J. Shear bond strength of orthodontic brackets bonded with a modified 1-step etchant-and-primer technique. Am. J. Orthod. Dentofacial Orthop., St. Louis, v. 124, no. 4, p. 410-413, Oct. 2003.

10. FARQUHAR, R. B. Direct bonding comparing a polyacrylic acid and a phosphoric acid technique. Am. J. Orthod. Dentofacial Orthop., St. Louis, v. 90, no. 3, p. 187-194, Sept. 1986.

11. GRANDHI, R. K.; COMBE, E. C.; SPEIDEL, T. M. Shear bond strength of stainless steel orthodontic brackets with a moistureinsensitive primer. Am. J. Orthod. Dentofacial Orthop., St. Louis, v. 119, no. 3, p. 251-255, Mar. 2001.

12. HOSEIN, I.; SHERRIF, M.; IRELAND, A. J. Enamel loss during bonding, debonding and cleanup with use of a self-etching primer. Am. J. Orthod. Dentofacial Orthop., St. Louis, v. 126, no. 6, p. 717-724, Dec. 2004.

13. IRELAND, A. J.; KNIGHT, H.; SHERRIFF, M. An in vivo investigation into bond failure rates with a new self-etching primer system. Am. J. Orthod. Dentofacial Orthop., St. Louis, v. 124, no. 3, p. 323-326, Sept. 2003.

14. ITOH, T.; FUKUSHIMA, T.; INOUE, Y.; ARITA, S.; MIYAZAKI, K. Effect of water, saliva and blood contamination on bonding of metal brackets with a 4-META/MMB/TBB resin to etched enamel. Am. J. Dent., St. Louis, v. 12, no. 6, p. 299-304, Dec. 1999.

15. JASSEM, H. A.; RETIEF, D. H.; JAMISON, H. C. Tensile and shear strengths of bonded and rebounded orthodontic attachments. Am. J. Orthod. Dentofacial Orthop., St. Louis, v. 79, no. 6, p. 661-668, June 1981. 
16. MENEZES, L. F. S. Influência do agente de união e da viscosidade do compósito em colagens ortodônticas 1991. Dissertação (Mestrado)-Faculdade de Odontologia, Universidade Federal do Rio de Janeiro, Rio de Janeiro, 1991.

17. MORAES, M.; SINHORETI, M. A. C.; CONSANI, S.; MIKAMI, J. R. Estudo comparativo entre procedimentos de colagem do botão ortodôntico para tracionamento de dentes retidos. Rev. Dental Press Ortodon. Ortop. Facial, Maringá, v. 3, n. 5 , p. 52-58, set./out. 1998.

18. PEREIRA, F. L.; IWAKI, L.; CAMARINI, E. T.; PAVAN, A. J. Estudo laboratorial de teste de resistência ao tracionamento da resina composta fotopolimerizável Fill Magic destinada à colagem de braquetes para tracionamento ortodôntico de dentes retidos. Rev. Dental Press Ortodon. Ortop. Facial, Maringá, v. 11, n. 1, p. 77-83, jan./fev. 2006

19. POWERS, J. M.; KIM, H.; TURNER, D. S. Orthodontic adhesives and bond strength testing. Semin. Orthod., Birmingham, v. 3, no. 3, p. 147-156, Sept. 1997.

20. RAJAGOPAL, R.; PADMANABHAN, S.; GNANAMANI, $J$. A comparison of shear bond strength and debonding characteristics of conventional, moisture-insensitive and selfetching primers in vitro. Angle Orthod., Appleton, v. 74, no. 2 , p. $264-268,2004$
21. REYNOLDS, I. R. A review of direct orthodontic bonding. Br. J. Orthod., London, v. 2, no. 2, p. 171-178, Apr. 1975

22. SCHANEVELDT, S.; FOLEY, T. F. Bond strength comparison of moisture-insensitive primers. Am. J. Orthod. Dentofacial Orthop., St. Louis, v. 122, no. 3, p. 267-273, Sept. 2002.

23. TORTAMANO, A.; VIGORITO, J. W.; NAUFF, F.; GARONE, G. M.; SANTOS, R. S. C. Evaluation of the tensile strength of cementing agents for orthodontic brackets. Rev. Assoc. Paul. Cir. Dent., São Paulo, v. 56, no. 4, p. 259-263, jul./ ago. 2002.

24. WEBSTER, M. J.; NANDA, R. S.; DUNCANSON, M. G.; KHAJOTIA, S. S.; SINHA, P. K. The effect of saliva on shear bond strengths of hydrophilic bonding systems. Am. J. Orthod. Dentofacial Orthop., St. Louis, v. 119, no. 1, p. 54-58, Jan. 2001.

25. ZEPPIERI, I. L.; CHUNG, C. O.; MANTE, F. K. Effect of saliva on shear bond strength of an orthodontic adhesive used with moisture-insensitive and self-etching primers. Am. J. Orthod. Dentofacial Orthop., St. Louis, v. 124, no. 4, p. 414-419, Oct. 2003.
Endereço para correspondência

Cristiane Becher Rosa

Centro de Ortodontia e Ortopedia Facial Prof. José Edimo Soares

Martins - Av. Araújo Pinho, 62, $7^{\circ}$ andar - Canela

CEP: 40.110-060 - Salvador/BA

E-mail: becherrosa@gmail.com 